\title{
A COMPARISON OF HIRUDIN WITH HEPARIN IN THE PREVENTION OF RESTENOSIS AFTER CORONARY ANGIOPLASTY
}

\author{
Patrick W. Serruys, M.D., Ph.D., Jean-Paul R. Herrman, M.D., Rudiger Simon, M.D., \\ Wolfgang Rutsch, M.D., Christoph Bode, M.D., Gert-Jan Laarman, M.D., Ph.D., \\ Rene van Dijk, M.D., Arjan A. van den Bos, M.D., Victor A.W.M. Umans, M.D., Ph.D., \\ Keith A.A. Fox, M.D., Philip Close, M.D., and JaAP W. Degkers, M.D., Ph.D., \\ FOr the Helvetica Investigators*
}

\begin{abstract}
Background. The likelihood of restenosis is a major limitation of coronary angioplasty. We studied whether hirudin, a highly selective inhibitor of thrombin with irreversible effects, would prevent restenosis after angioplasty. We compared two regimens of recombinant hirudin with heparin.

Methods. We randomly assigned 1141 patients with unstable angina who were scheduled for angioplasty to receive one of three treatments: (1) a bolus dose of $10,000 \mathrm{IU}$ of heparin followed by an intravenous infusion of heparin for 24 hours and subcutaneous placebo twice daily for three days (382 patients), (2) a bolus dose of 40 $\mathrm{mg}$ of hirudin followed by an intravenous infusion of hirudin for 24 hours and subcutaneous placebo twice daily for three days (381 patients), or (3) the same hirudin regimen except that $40 \mathrm{mg}$ of hirudin was given subcutaneously instead of placebo twice daily for three days (378 patients). The primary end point was event-free survival at seven months. Other end points were early cardiac events (with-
\end{abstract}

$\mathrm{P}$ LATELET aggregation, the generation of thrombin, and the release of growth factors at the site of angioplasty have all been implicated in the process of restenosis. ${ }^{1,2}$ Consequently, anticoagulants, antiplatelet agents, and specific antithrombin agents have been considered for the prevention of restenosis. ${ }^{3}$ Thrombin is the most potent platelet activator known, stimulating the production of platelet-derived growth factor and the secretion of prostacyclin, platelet-activating factor, and plasminogen-activator inhibitor. Thrombin has apparent mitogenic effects on lymphocytes and vascular smooth-muscle cells., ${ }^{4,5}$

Hirudin, a 65-amino-acid compound originally extracted from the salivary gland of the leech, is a specific inhibitor of thrombin. The advantage of hirudin over other serine protease inhibitors is its potency in irreversibly blocking thrombin at multiple sites without the need for circulating antithrombin III. ${ }^{6}$ Because of the small size of the hirudin molecule, this substance can inhibit clot-bound thrombin and restrict the further formation of thrombus. ${ }^{7}$

Hirudin has reduced the deposition of platelets after vascular injury in pigs ${ }^{8}$ and lowered the rate of reste-

From the Academisch Ziekenhuis Dijkzigt, Rotterdam, the Netherlands (P.W.S., J.-P.R.H., V.A.W.M.U.); the Medizinische Universitätsklinik, Kiel, Germany (R.S.); the Universitätsklinik Rudolf Virchow, Berlin, Germany (W.R.); the Medizinische Klinik III, Heidelberg, Germany (C.B.); the Onze Lieve Vrouwe Gasthuis, Amsterdam (G.-J.L.); the Academisch Ziekenhuis Groningen, Groningen, the Netherlands (R.D.); the Medisch Centrum de Klokkenberg, Breda, the Netherlands (A.A.B.); the Royal Infirmary, Edinburgh, United Kingdom (K.A.A.F.); Ciba-Geigy Ltd., Basel, Switzerland (P.C.); and Cardialysis B.V., Rotterdam, the Netherlands (J.W.D.). Address reprint requests to Dr. Serruys at the Thoraxcenter, Erasmus University, Rm. EE 2332, P.O. Box 1738, 3000 DR Rotterdam, the Netherlands.

*The institutions and investigators participating in the Helvetica trial are listed in the Appendix in 96 hours), bleeding and other complications of the study treatment, and angiographic measurements of coronary diameter at six months of follow-up.

Results. At seven months, event-free survival was 67.3 percent in the group receiving heparin, 63.5 percent in the group receiving intravenous hirudin, and 68.0 percent in the group receiving both intravenous and subcutaneous hirudin $(P=0.61)$. However, the administration of hirudin was associated with a significant reduction in early cardiac events, which occurred in 11.0, 7.9, and 5.6 percent of patients in the respective groups (combined relative risk with hirudin, $0.61 ; 95$ percent confidence interval, 0.41 to $0.90 ; P=0.023$ ). The mean minimal luminal diameters in the respective groups on follow-up angiography at six months were $1.54,1.47$, and $1.56 \mathrm{~mm}(P=0.08)$.

Conclusions. Although significantly fewer early cardiac events occurred with hirudin than with heparin, hirudin had no apparent benefit with longer-term follow-up. (N Engl J Med 1995;333:757-63.)

nosis in hypercholesterolemic rabbits, ${ }^{9}$ providing a rationale for its use in patients undergoing angioplasty. In this trial we evaluated whether the inhibition of thrombin with hirudin as compared with heparin improved event-free survival in patients undergoing coronary angioplasty.

\section{Methods}

\section{Study Population}

Patients with unstable angina and one or more clinically important new or restenotic coronary narrowings suitable for treatment with percutaneous transluminal coronary angioplasty were eligible for the study. From September 1992 through May 1993, 1154 patients from various institutions (listed in the Appendix) were randomized. All had unstable angina, as defined by the new onset of angina pectoris or the worsening of angina (i.e., their condition changed by two or more classes according to the classification system of the Canadian Cardiovascular Society ${ }^{10}$ or they needed additional antianginal medication), angina at rest, or both in the preceding three months. ${ }^{11}$ The criteria for exclusion from the study were stable angina, a planned multistage angioplasty procedure or stent implantation, myocardial infarction occurring within the preceding two weeks, hypertension, diabetic retinopathy, and body weight over $100 \mathrm{~kg}$.

The study was conducted in accordance with the principles of the Declaration of Helsinki and its subsequent amendments and with the laws and regulations of the countries where the trial took place. Before randomization, each patient gave written informed consent.

\section{Antithrombin Regimens}

The patients were randomly assigned in a double-blind fashion to receive recombinant hirudin (Revasc, Ciba-Geigy, Basel, Switzerland ${ }^{12}$ ) in one of two dose regimens or to receive unfractionated sodium heparin. The randomization was stratified according to whether heparin had been administered in the preceding 24 hours. Heparin therapy had to be discontinued at least 30 minutes before the start of treatment with the study medication.

The patients received one of the following three treatments: heparin (an intravenous bolus injection of 10,000 IU of heparin followed by a continuous intravenous infusion of $15 \mathrm{IU}$ of heparin per kilogram 
of body weight per hour for 24 hours, with placebo given subcutaneously twice daily for three consecutive days), intravenous hirudin (an intravenous bolus injection of $40 \mathrm{mg}$ of hirudin followed by a continuous intravenous infusion of $0.2 \mathrm{mg}$ of hirudin per kilogram per hour for 24 hours, with placebo given subcutaneously twice daily for three consecutive days), or intravenous and subcutaneous hirudin (an intravenous bolus injection of $40 \mathrm{mg}$ of hirudin followed by a continuous intravenous infusion of $0.2 \mathrm{mg}$ of hirudin per kilogram per hour for 24 hours, with $40 \mathrm{mg}$ of hirudin given subcutaneously twice daily for three consecutive days). If the angioplasty lasted more than one hour, an additional bolus dose of $5000 \mathrm{IU}$ of heparin could be administered at the option of the physician to the patients in the heparin group, or an equivalent amount of placebo could be given to the patients in the hirudin groups. The operators remained blinded to the results of clotting studies, and no adjustment of the rate of infusion of the study medication was allowed. A concomitant dose of aspirin (100 to 500 $\mathrm{mg}$ once daily) was given on the day of angioplasty, and this treatment was continued for at least 14 days.

\section{Criteria for Evaluation}

\section{Efficacy}

The primary end point was event-free survival 30 weeks after angioplasty - that is, the absence of death, nonfatal myocardial infarction, coronary-artery bypass grafting or the use of a "bailout" procedure (e.g., stenting), or second angioplasty at previously dilated sites. Myocardial infarction was diagnosed on the basis of new $Q$ waves (according to the Minnesota Code ${ }^{13}$ ) or an increase in the serum creatine kinase level to more than twice the upper limit of the normal range, with a concomitant increase in the $\mathrm{MB}$ fraction. If a stent was implanted electively after the initial angioplasty (i.e., not as part of a bailout procedure), the implantation was considered equivalent to a second angioplasty. Second angioplasty or bypass surgery needed to be preceded by typical anginal symptoms or, if there were atypical anginal symptoms, by electrocardiographic evidence of myocardial ischemia at rest or during exercise and an angiographically determined stenosis greater than 50 percent by visual inspection.

Secondary end points were as follows: any of a ranked series of clinical events that included death from cardiac causes, nonfatal myocardial infarction, coronary-artery bypass grafting (or the use of a bailout procedure), second angioplasty, and anginal status (according to the classification system of the Canadian Cardiovascular Society ${ }^{10}$ ) at the 30-week follow-up evaluation; the occurrence of any of these events within 96 hours after the start of the study medication; the minimal luminal diameter of the dilated sites as measured by quantitative coronary angiography at the 26-week follow-up evaluation; and any change in the minimal luminal diameter of dilated sites from immediately after angioplasty to follow-up angiography at 26 weeks.

\section{Safety}

Safety was evaluated with regard to bleeding and other complications. Bleeding was classified as major if it was overt and led to a decrease in the hemoglobin level by at least $2 \mathrm{~g}$ per deciliter; if it necessitated the transfusion of two or more units of whole blood or packed cells; or if it occurred intracranially, retroperitoneally, or at the site of a major joint..$^{14}$ Minor bleeding was defined as overt bleeding that did not meet these criteria.

\section{Angiography and Assessment of Coagulation}

For each patient, coronary angiograms were obtained in a standardized fashion immediately before and immediately after angioplasty, and at the six-month follow-up evaluation. The angiograms were analyzed in a core laboratory with the Cardiovascular Angiography Analysis System..$^{15,16}$

Blood samples for the measurement of coagulation were obtained at regular intervals before and after angioplasty. Blood samples for the determination of activated partial-thromboplastin times and levels of prothrombin fragment $\mathrm{F}_{1+2}$ (a measure of the generation of thrombin) were obtained separately by atraumatic venipuncture and were analyzed in a central laboratory.

\section{Statistical Analysis}

Outcomes were compared in an intention-to-treat analysis, which included all randomized patients in whom coronary angioplasty was attempted. Patients in whom no angioplasty was attempted (i.e., those whose indication for angioplasty changed or disappeared) were excluded from the analysis. A successful procedure was defined as one in which the stenosis was reduced by more than half; in the case of a failed recanalization of a total occlusion, the second lesion treated was considered to be the first site of angioplasty.

The distribution of event-free survival at 30 weeks was calculated according to the method of Kaplan and Meier, and distributions were compared by the Kruskal-Wallis test ${ }^{17}$; for patients with multiple events, the first event was considered. Event rates and rates of bleeding and other complications were compared by the chi-square test.

A linear logistic-regression analysis for ordered categories was performed for the ranked clinical outcomes, with pretreatment with heparin used as a covariate. The most severe event in each patient was considered in the analysis.

The minimal luminal diameters at the dilated sites 26 weeks after angioplasty were compared by analysis of variance, with the mean value for all sites used in cases of angioplasty at multiple sites. All reported $\mathrm{P}$ values are two-tailed. Whenever possible, estimates of the magnitude of the treatment effect are provided, with corresponding 95 percent confidence intervals. Relative risks are presented for the combined hirudin groups as compared with the heparin group.

\section{RESULTS}

\section{Study Population}

A total of 1154 patients were randomized. Of 5686 patients screened, 21 percent were ineligible because they had stable angina, 16 percent for reasons involving logistics, and 11 percent because they had had myocardial infarctions during the previous two weeks. The remaining screened patients (32 percent) were excluded for a wide variety of reasons. Thirteen patients

Table 1. Base-Line Characteristics of the Study Patients According to Group Assignment.*

\begin{tabular}{|c|c|c|c|}
\hline CHARACTERISTIC $\dagger$ & $\begin{array}{l}\text { HEPARIN } \\
(\mathrm{N}=382)\end{array}$ & $\begin{array}{c}\text { INTRAVENOUS } \\
\text { HIRUDIN } \\
(\mathrm{N}=381)\end{array}$ & $\begin{array}{c}\text { INTRAVENOUS AND } \\
\text { SUBCUTANEOUS } \\
\text { HIRUDIN } \\
(\mathrm{N}=378)\end{array}$ \\
\hline Male sex & $299(78.3)$ & $300(78.7)$ & $297(78.6)$ \\
\hline Age (yr) & $58.2 \pm 8.7$ & $58.7 \pm 9.1$ & $58.8 \pm 8.9$ \\
\hline Weight $(\mathrm{kg})$ & $76.0 \pm 10.9$ & $75.9 \pm 11.1$ & $76.7 \pm 10.7$ \\
\hline Smoker & $104(27.2)$ & $90(23.6)$ & $84(22.2)$ \\
\hline Diabetes & $44(11.5)$ & $42(11.0)$ & $40(10.6)$ \\
\hline Previous MI & $148(38.7)$ & $152(39.9)$ & $154(40.7)$ \\
\hline Previous $\mathrm{CABG}$ & $10(2.6)$ & $8(2.1)$ & $20(5.3)$ \\
\hline Previous angioplasty & $69(18.1)$ & $69(18.1)$ & $64(16.9)$ \\
\hline \multicolumn{4}{|l|}{ Braunwald class } \\
\hline I & $131(34.3)$ & $146(38.3)$ & $139(36.8)$ \\
\hline II & $163(42.7)$ & $160(42.0)$ & $166(43.9)$ \\
\hline III & $88(23.0)$ & 75 (19.7) & $73(19.3)$ \\
\hline \multicolumn{4}{|l|}{$\begin{array}{c}\text { Exertional angina - } \\
\text { CCS class }\end{array}$} \\
\hline 1 & 7 (1.8) & $10(2.6)$ & $6(1.6)$ \\
\hline 2 & $82(21.5)$ & $69(18.1)$ & 66 (17.5) \\
\hline 3 & $144(37.7)$ & $163(42.8)$ & $171(45.2)$ \\
\hline 4 & $102(26.7)$ & $96(25.2)$ & $89(23.5)$ \\
\hline IV heparin used at screening & $115(30.1)$ & $110(28.9)$ & $109(28.8)$ \\
\hline \multicolumn{4}{|l|}{ Lesions } \\
\hline Total no. & 482 & 483 & 462 \\
\hline Mean no. per patient & 1.26 & 1.27 & 1.22 \\
\hline \multicolumn{4}{|l|}{ Location before angioplasty } \\
\hline RCA & $148(30.7)$ & $136(28.2)$ & $139(30.1)$ \\
\hline LAD & $230(47.7)$ & $238(49.2)$ & $201(54.5)$ \\
\hline LCX & $104(21.6)$ & $109(22.6)$ & $121(26.2)$ \\
\hline LM & 0 & 0 & $1(0.2)$ \\
\hline
\end{tabular}

*Plus-minus values are means \pm SD. Except as noted, all other values are numbers of patients followed in parentheses by the percentage of the group.

$\dagger$ MI denotes myocardial infarction, CABG coronary-artery bypass graft surgery, CCS Canadian Cardiovascular Society, IV intravenous, RCA right coronary artery, LAD left anterior descending coronary artery, LCX left circumflex coronary artery, and LM left main coronary artery. 


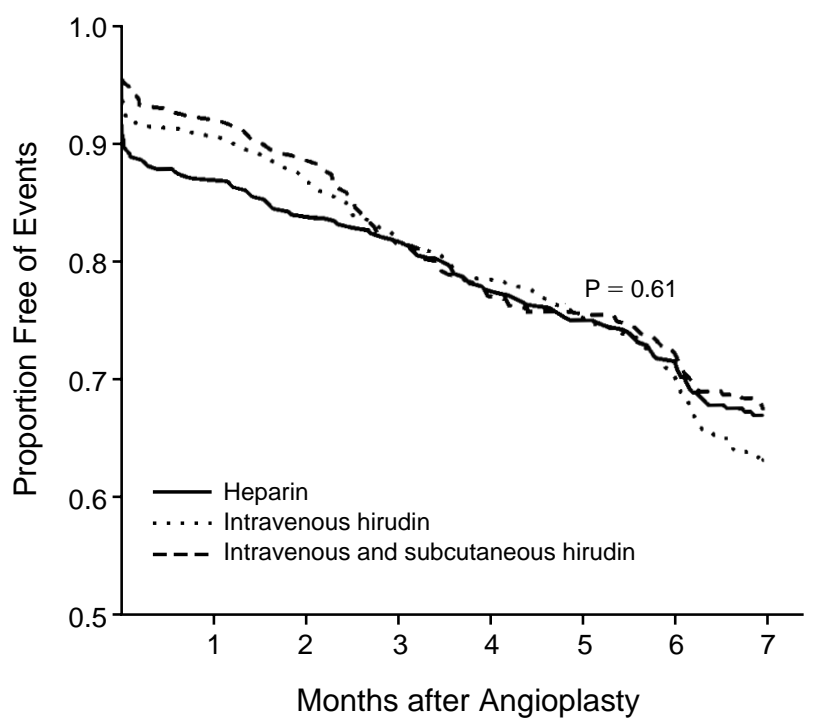

Figure 1. Kaplan-Meier Distribution of Patients without Events in the Intention-to-Treat Analysis ( $\mathrm{N}=1141)$.

The groups were compared by the Kruskal-Wallis test.

were not included in the intention-to-treat analysis because no angioplasty was attempted. Among the remaining 1141 patients in whom angioplasty was attempted, 382 were randomly assigned to heparin, 381 to intravenous hirudin, and 378 to intravenous and subcutaneous hirudin. Angioplasty was successful in 91.7 percent, and the results of angiographic follow-up were available for 86.4 percent. Clinical follow-up was complete for all but one patient.

The clinical and angiographic characteristics of the patients at base line are shown in Table 1. The characteristics of the three groups were similar. Almost one third of the patients received intravenous heparin before randomization because of the severity of their unstable angina.

\section{Efficacy}

Among the study patients, 125 patients assigned to heparin, 139 assigned to intravenous hirudin, and 121 assigned to intravenous and subcutaneous hirudin reached a primary end point. The distribution of patients free of events is shown in Figure 1. No significant differences were observed among the treatment groups ( $\mathrm{P}=0.61$ by the Kruskal-Wallis test), even after stratification according to pretreatment with heparin.

The incidence of clinical events and angina at 30 weeks is shown in Table 2, with no significant differences among the three groups $(\mathrm{P}=0.61)$. An analysis of subgroups according to whether patients were pretreated with heparin yielded similar results.

The incidence of early events (those occurring in the first 96 hours after angioplasty) is also shown in Table 2. Forty-two patients assigned to heparin, 30 patients assigned to intravenous hirudin, and 21 patients assigned to intravenous and subcutaneous hirudin had such events (relative risk in the combined hirudin groups, $0.61 ; 95$ percent confidence interval, 0.41 to $0.90 ; \mathrm{P}=0.023)$. Among the patients pretreated with heparin, there were 20,7 , and 7 events, respectively (combined relative risk with hirudin, 0.37; 95 percent confidence interval, 0.19 to $0.70 ; \mathrm{P}=0.007$ ). Because these results suggested a particular benefit of hirudin in the most unstable patients (those with Braunwald class III angina), an additional analysis was performed of the 236 patients who had angina at rest during the 48 hours before randomization. The event rate among these patients was 21.6 percent in the heparin group, as compared with 5.3 percent among patients receiving intravenous hirudin and 12.3 percent among patients receiving intravenous and subcutaneous hirudin (combined relative risk with hirudin, 0.41 ; 95 percent confidence interval, 0.21 to $0.78 ; \mathrm{P}=0.006$ ).

The imbalance in the number of deaths (Table 2) calls for a description of their exact causes. In the heparin group, three myocardial infarctions and one nonhemorrhagic cerebrovascular accident resulted in death. In the group receiving intravenous hirudin, there was one sudden death. In the group receiving intravenous and subcutaneous hirudin, five patients had fatal myocardial infarctions. In this group there were also two cerebrovascular accidents (one of which was hemorrhagic), one episode of cardiac tamponade, and one sudden death; one patient died of respiratory insufficiency, and one of wound infection and sepsis after bypass surgery.

Linear logistic-regression analysis of ordered categorical data revealed that pretreatment with heparin

Table 2. Clinical Events in the First 96 Hours and the First 30 Weeks in the Intention-to-Treat Analysis.*

\begin{tabular}{|c|c|c|c|c|c|c|}
\hline \multirow[t]{2}{*}{ EVENT } & \multicolumn{2}{|c|}{ HEPARIN $(\mathrm{N}=382)$} & \multicolumn{2}{|c|}{ INTRAVENOUS HIRUDIN $(\mathrm{N}=381$ ) } & \multicolumn{2}{|c|}{$\begin{array}{c}\text { InTRAVENOUS AND SUBCUTANEOUS } \\
\text { HIRUDIN }(\mathrm{N}=378)\end{array}$} \\
\hline & $96 \mathrm{HR}$ & $30 \mathrm{wK}$ & $96 \mathrm{HR}$ & $30 \mathrm{wK}$ & $96 \mathrm{HR}$ & $30 \mathrm{wK}$ \\
\hline & \multicolumn{6}{|c|}{ number (percent) } \\
\hline Death & $2(0.5)$ & $4(1.0)$ & 0 & $1(0.3)$ & 0 & $11(2.9)$ \\
\hline Myocardial infarction & $16(4.2)$ & $20(5.2)$ & $13(3.4)$ & $19(5.0)$ & $9(2.4)$ & $23(6.1)$ \\
\hline Coronary bypass surgery & $9(2.4)$ & $21(5.5)$ & $6(1.6)$ & $21(5.5)$ & $3(0.8)$ & $25(6.6)$ \\
\hline Bailout procedure & $18(4.7)$ & $18(4.7)$ & $12(3.1)$ & $12(3.1)$ & $8(2.1)$ & $8(2.1)$ \\
\hline Second angioplasty & $13(3.4)$ & $91(23.8)$ & $7(1.8)$ & 109 (28.6) & $5(1.3)$ & $93(24.6)$ \\
\hline Any event & $42(11.0)$ & $125(32.7)$ & $30(7.9)$ & $139(36.5)$ & $21(5.6)$ & $121(32.0)$ \\
\hline Any exertional angina & - & $55(14.4)$ & - & $71(18.6)$ & - & $71(18.8)$ \\
\hline No events or symptoms & - & $202(52.9)$ & - & $171(44.9)$ & - & $186(49.2)$ \\
\hline
\end{tabular}

*At 96 hours, the combined relative risk in the hirudin groups as compared with the heparin group was 0.61 (95 percent confidence interval, 0.41 to 0.90 ; $\mathrm{P}=0.023$ ). 
was significantly associated with worse clinical outcomes at seven months $(\mathrm{P}=0.03)$. The type of study medication did not influence outcome in this model.

Base-line angiographic measurements and gains in luminal diameter achieved by angioplasty were similar in the three groups (Table 3). The changes in minimal luminal diameter from immediately after angioplasty to follow-up were also similar (Fig. 2).

\section{Safety}

The incidence of bleeding complications is shown in Table 4. No differences with respect to major or minor bleeding were observed among groups. There were three cerebrovascular accidents. One patient receiving intravenous and subcutaneous hirudin was readmitted to the hospital with hemiplegia 14 hours after the final subcutaneous injection; despite surgical evacuation of the intracerebral hematoma causing the condition, the patient died six days after the start of the study treatment. Two intracerebral thrombotic events were observed. One patient (receiving intravenous and subcutaneous hirudin), who presented with symptoms of neurologic deficit one day after discharge from the hospital and who had multiple brain infarctions on computed axial tomography, died five days after the start of the study treatment. Another patient (in the heparin group) presented with massive pulmonary embolism. Paradoxical embolization through a patent foramen ovale caused an extensive, expanding cerebral infarction and led to the patient's death eight days after the start of the study medication.

\section{Anticoagulant Effects}

Levels of prothrombin fragment $\mathrm{F}_{1+2}$ are shown in Figure 3. The median levels peaked in both hirudin groups at the end of the procedure (from $1.1 \mathrm{nmol}$ per liter at the time of screening to $1.4 \mathrm{nmol}$ per liter in the group receiving intravenous hirudin, and from 1.0 to $1.3 \mathrm{nmol}$ per liter in the group receiving intravenous and subcutaneous hirudin), whereas in the heparin group the levels were slightly reduced (to $0.9 \mathrm{nmol}$ per liter) as compared with those at the time of screening (1.0 nmol per liter). Levels of prothrombin fragment

Table 3. Mean $( \pm S D)$ Angiographic Measurements in the Intention-to-Treat Analysis of Patients for Whom Follow-up Data Were Available.

\begin{tabular}{lccc}
\hline \hline & $\begin{array}{c}\text { HEPARIN } \\
(\mathrm{N}=330)\end{array}$ & $\begin{array}{c}\text { INTRAVENOUS } \\
\text { HIRUDIN } \\
(\mathrm{N}=341)\end{array}$ & $\begin{array}{c}\text { INTRAVENOUS } \\
\text { AND } \\
\text { SUBCUTANEOUS } \\
\text { HIRUDIN } \\
(\mathrm{N}=315)\end{array}$ \\
VARIABLE & & millimeters & \\
& & & \\
Reference luminal diameter* & $2.69 \pm 0.51$ & $2.67 \pm 0.51$ & $2.70 \pm 0.51$ \\
Minimal luminal diameter & & & \\
$\quad$ Before angioplasty & $0.99 \pm 0.38$ & $0.97 \pm 0.39$ & $1.03 \pm 0.35$ \\
$\quad$ After angioplasty & $1.80 \pm 0.37$ & $1.78 \pm 0.36$ & $1.82 \pm 0.37$ \\
$\quad$ At follow-up & $1.54 \pm 0.59$ & $1.47 \pm 0.56$ & $1.56 \pm 0.50$ \\
Gain & $0.81 \pm 0.41$ & $0.82 \pm 0.44$ & $0.79 \pm 0.41$ \\
Loss & $0.26 \pm 0.52$ & $0.32 \pm 0.50$ & $0.26 \pm 0.45$ \\
\hline
\end{tabular}

*As estimated by computer techniques on the basis of the diameters of segments proximal and distal to the site of stenosis.

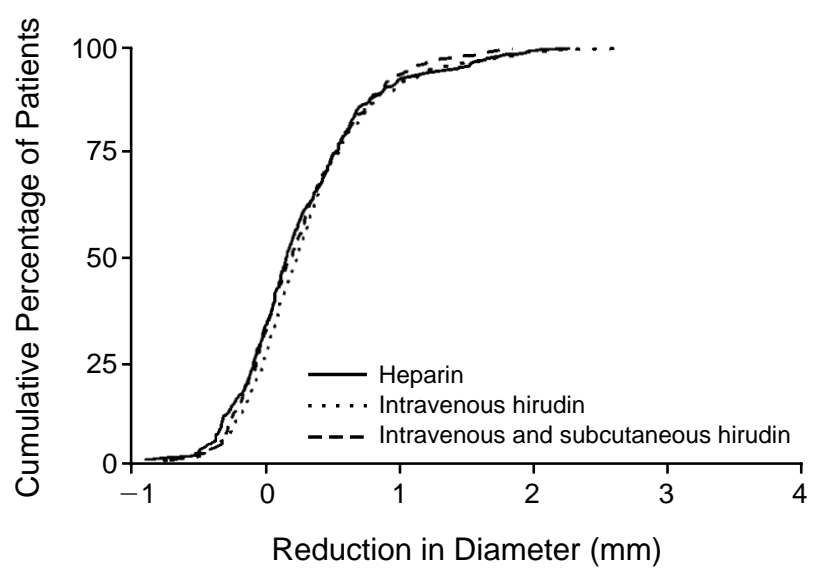

Figure 2. Cumulative Distribution of the Reduction in Minimal Luminal Diameter from Immediately after Angioplasty to Follow-up at Seven Months.

$\mathrm{F}_{1+2}$ measured at 24,96 , and 98 hours subsequently returned to the base-line values in all three groups.

Measurements of activated partial-thromboplastin time (Fig. 3) were higher at the end of the procedure in the subjects receiving heparin than in those receiving hirudin, an effect that disappeared after 24 hours. The infusion of hirudin resulted in a more stable effect. Slightly prolonged activated partial-thromboplastin times were observed at 96 hours after angioplasty in the group receiving intravenous and subcutaneous hirudin.

\section{Discussion}

Although hirudin was associated with impressive reductions in the rate of major cardiac events in the first 96 hours after angioplasty as compared with heparin, the primary goal of this trial, a reduction in the rate of cardiac events at seven months, was not accomplished. Event-free survival at seven months did not differ among the treatment groups.

At least three other trials using specific antiplatelet drugs have demonstrated beneficial effects on the acute complications of coronary angioplasty without favorably influencing long-term clinical outcomes. ${ }^{18-20}$ These findings differ from the results of the Evaluation of 7E3 for the Prevention of Ischemic Complications (EPIC) trial, ${ }^{21,22}$ in which the glycoprotein $\mathrm{IIb} / \mathrm{III}$ a receptor was presumed to have been blocked completely and which showed a reduction in early cardiac events that was maintained with longer-term follow-up.

The dosage and duration of treatment in the present trial were chosen as a compromise among safety issues, logistic considerations, and the scientific evidence available when the trial was designed. Primarily, the dosage was based on safety data obtained in healthy volunteers, stable patients undergoing angioplasty, and patients undergoing orthopedic surgery. ${ }^{23-25}$ However, the results of assays of prothrombin fragment $\mathrm{F}_{1+2}$ immediately after angioplasty suggest that the generation of thrombin was not satisfactorily inhibited in either hirudin group, whereas the dosage of heparin we used resulted in an appropriate decrease in levels of prothrom- 
Table 4. Bleeding Complications.

\begin{tabular}{|c|c|c|c|}
\hline \multirow[t]{2}{*}{ COMPLICATION } & \multicolumn{3}{|c|}{ 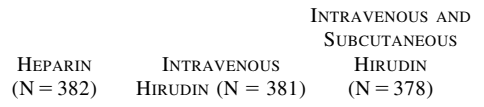 } \\
\hline & \multicolumn{3}{|c|}{ number (percent) of patients } \\
\hline \multicolumn{4}{|l|}{ Major bleeding } \\
\hline $\begin{array}{l}\text { Overt, with decrease in hemo- } \\
\text { globin by } \geqslant 2 \mathrm{~g} / \mathrm{dl}\end{array}$ & $24(6.2)$ & $18(4.7)$ & $28(7.4)$ \\
\hline $\begin{array}{l}\text { Overt, requiring transfusion } \\
\text { of } \geqslant 2 \text { units whole blood } \\
\text { or packed cells }\end{array}$ & 0 & $3(0.8)$ & 0 \\
\hline Intracranial & 0 & 0 & $1(0.3)$ \\
\hline $\begin{array}{l}\text { Retroperitoneal or in a } \\
\text { major joint }\end{array}$ & 0 & 0 & 0 \\
\hline All & $24(6.2)$ & $21(5.5)$ & $29(7.7)$ \\
\hline Minor bleeding & $43(11.3)$ & $50(13.1)$ & $57(15.1)$ \\
\hline
\end{tabular}

bin fragment $\mathrm{F}_{1+2}$ at six hours. It can be inferred from these data that the adjustment in the infusion rate from $0.16 \mathrm{mg}$ per kilogram per hour in the pilot study of patients with stable angina ${ }^{25}$ to $0.20 \mathrm{mg}$ per kilogram per hour in the current trial of patients with unstable angina and presumably higher levels of thrombin generation - was too cautious a change in dosage. Zoldhelyi et al. ${ }^{26}$ recently reported failing to block the generation of thrombin in their patients despite the presence of a 10,000-fold molar excess of free hirudin over the amount bound in complexes with thrombin. Infusion rates of hirudin in experiments with animals were as much as five times higher than those currently used, a finding that may explain the lack of a long-term effect in the present study.,9

When hirudin was administered subcutaneously in healthy volunteers at a dose of $0.5 \mathrm{mg}$ per kilogram twice daily, the activated partial-thromboplastin time 12 hours after the first injection was subtherapeutic, ${ }^{23}$ and it may be inferred that the inhibition of the conversion of prothrombin was also inadequate in the first three days of the trial. A putative explanation for the apparent paradox by which the early outcome is improved although there is less appropriate control of thrombin may be that the dosage used was not sufficient to produce an adequate level of anticoagulation, but was sufficient to limit the thrombin-mediated aggregation and activation of platelets, causing effects similar to those observed over the short term in the EPIC trial. ${ }^{8,21,22}$

The optimal duration of treatment is unknown, even in animal models. Conflicting findings about the time course of thrombogenicity in the injured vessel wall have been reported. ${ }^{27-30}$ In this study we decided to maintain our patients at effective levels of antithrombin activity as long as possible. Since ethical considerations necessitated monitoring the patients' safety in the hospital during the subcutaneous injections of hirudin, a reasonable compromise between the duration of hirudin administration and logistic considerations of the trial was presumably achieved by administering the
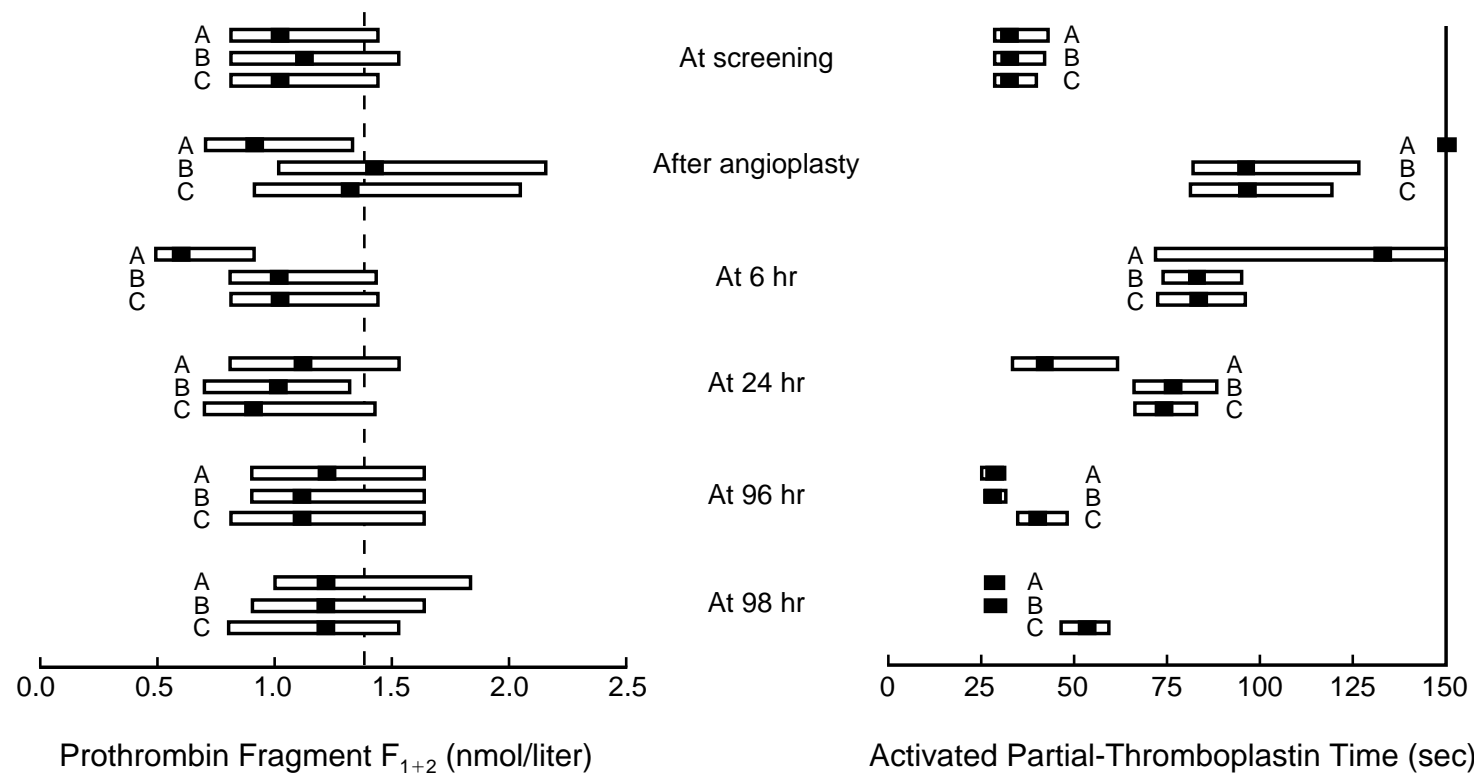

Figure 3. Levels of Prothrombin Fragment $F_{1+2}$ and Activated Partial-Thromboplastin Times in the Three Study Groups at Various Times before and after Angioplasty.

A denotes the group receiving heparin, B the group receiving intravenous hirudin, and $\mathrm{C}$ the group receiving intravenous and subcutaneous hirudin. The solid area inside each box indicates the median value, and the left and right margins of the box indicate the upper limits of the first and third quartiles, respectively.

In the left-hand panel, the dotted vertical line indicates the upper limit of the normal level of prothrombin fragment $F_{1+2}(1.4 \mathrm{nmol}$ per liter). Heparin tended to control the generation of thrombin better than hirudin both immediately after angioplasty and six hours after the start of the infusion.

In the right-hand panel, the activated partial-thromboplastin time was measured up to a maximum of 150 seconds. Over the first 24 hours this value was more than double the base-line value in the hirudin-treated groups, whereas in the heparin-treated group it returned almost to the base-line level. 
drug intravenously for 24 hours and subcutaneously for three consecutive days.

A clearly beneficial effect of hirudin on platelet aggregation and thrombus formation was indicated by the prevention of acute ischemic events early after angioplasty. The failure of hirudin in this trial to alter longer-term outcomes indicates either that thrombin generation and thrombus formation in the period immediately after angioplasty may be less important in the process of restenosis than was previously believed or that complete reversal of the thrombogenicity of the injured vessel wall was not achieved or requires more time. Whether the large decrease in major events observed with hirudin early after the infusion can be translated to an improved long-term outcome with prolonged subcutaneous administration of hirudin deserves further study.

We are indebted to David P. Foley, M.D., and Peter N. Ruygrok, M.D., for their criticisms and comments, and to Wanda H. Wentowski for her expert assistance in the preparation of the manuscript.

\section{APPENDix}

The following institutions and investigators participated in the Helvetica (Hirudin in a European Trial versus Heparin in the Prevention of Restenosis after PTCA) trial. The number of patients enrolled at each center is given in parentheses, followed by an asterisk when all patients in the cardiac catheterization laboratory at a center were screened and the results entered in a logbook.

Medizinische Klinik III, Heidelberg, Germany (66)* — C. Bode, G. Schuler, S. Abed, H. Baumann; Universitätsklinik Rudolf Virchow, Berlin (66)* — W. Rutsch, C. Brunckhurst, N. Kokott; Medizinische Universitätsklinik, Kiel, Germany (66)* - R. Simon, M. Lins, G. Herrmann; Onze Lieve Vrouwe Gasthuis, Amsterdam (60)* - G. J. Laarman, F. Kiemeneij, H. Swart; Medisch Centrum de Klokkenberg, Breda, the Netherlands (54)* — A. van den Bos, M. Quarles van Ufford, U. Ghin-Kon-Sung, G. Uytdehaag; Academisch Ziekenhuis Groningen, Groningen, the Netherlands (54) R. van Dijk, P. Den Heyer, L. Drok, J. Klein; Istituto Apparato Cardiovascolare, Bologna, Italy (54)* - A. Marzocchi, G. Piovaccari, C. Marrozinni, E. Cere; Academisch Ziekenhuis Dijkzigt, Rotterdam, the Netherlands (54)* — P. Serruys, P. de Feyter, V. Umans, J. Herrman; Ospedali Riuniti, Bergamo, Italy (53)* — G. Guagliumi, O. Valsecchi, A. Casari, A. Piti', A. Tasca; Medizinische Universitätsklinik, Freiburg, Germany (52)* - A. Zeiher, H. Wollschläger, V. Schächinger; Hospital General Gregorio Maranon, Madrid (48)* - J. Delcan Dominguez, E. Garcia, J. Joriano, J. Elizaga; Sahlgrenska Hospital, Göteborg, Sweden (48)* - H. Emanuelsson, P. Albertsson, P. Hardhammar, L. Ekström; Hospital Clinico San Carlos, Madrid (48)* - C. Macaya, F. Alfonso, R. Hernandez, A. Iniguez; CHU Sart Tilman, Liège, Belgium (44)* - V. Legrand, M. Bellekens, P. Marcelle, P. Doneux; Ospedale di Circolo, Varese, Italy (36)* — G. Binaghi, S. Repetto, E. Verna, B. Castiglioni; Hospital Marques de Valdecilla, Santander, Spain $(30)^{*}$ — T. Colman, J. Zueco, A. Figueroa; U.C.L. Saint-Luc, Brussels, Belgium (30)* C. Hanet, W. Wijns, J. Cosyns, X. Michel; Ospedale Maggiore, Trieste, Italy (30)* - S. Klugmann, E. Della Grazia, L. Barbieri; Hôpital Universitaire de Mont-Godinne, Yvoir, Belgium (30)* E. Schroeder, P. Chenu, D. Grolaux; CHR Nancy, Vandoeuvreles-Nancy, France (26)* - N. Danchin, Y. Juilliere, F. Cherrier, C. Kettani; Onze Lieve Vrouwziekenhuis, Aalst, Belgium (26)* G. Heyndrickx, B. de Bruyne, M. Goethals, P. Goemare; Franz Volhard Klinik, Berlin-Buch, Germany (24)* - D. Gulba, G. Claus, S. Hauck; Centre Cardiologique du Nord, Saint Denis, France (24)* - M.-C. Morice, T. Royer, B. Glatt, E. Rosenblatt; Ziekenhuis de Weezenlanden, Zwolle, the Netherlands (24) - F. Zijlstra, H. Suryapranata, H. Schoenmaker, G. Velsink; Hospital Clinic i Provincial, Barcelona, Spain (23)* - A. Betriu, A. Serra, G. Sanz, M. Heras; Catharina Ziekenhuis, Eindhoven, the Netherlands (18)* - J. Bonnier, N. Pijls, M. el Gamal, S. Rouffel; Ospedale Nuguarda, Milan, Italy (18)* — L. Campolo; Policlinico San Matteo, Pavia, It- aly (18)* — G. Specchia, S. de Servi, F. Marisco; Centre Chirurgical Marie Lannelongue, Les Plessis Robinson, France (15)* — B. Lancelin, B. Chevalier, P. Guyon, F. Philippe; CHRU Rouen Hôpital, Rouen, France (15)* - B. Letac, H. Eltchaninoff, R. Koning, A. Cribier.

Steering Committee: P.W. Serruys (chairman), A. Betriu, F. Camerini (Ospedale Maggiore, Trieste, Italy), N. Danchin (Hôpital Brabois, Vandoeuvre-les-Nancy, France), H. Emanuelsson, W. Rutsch, A. van den Bos, P. Close, J.W. Deckers, R. Kerry (Pharma Division, CibaGeigy Ltd., Basel, Switzerland), J. Rijnierse (Ciba-Geigy, Arnhem, the Netherlands), P. Peerboom (Cardialysis, Rotterdam), V. Umans. Sponsor (Ciba-Geigy, Basel, Switzerland): P. Close, R. Kerry, P. Kobi. Angiographic Core Laboratory (Cardialysis, Rotterdam): L. Rodenburg, P.F. Peerboom, E. Nibbering, J. Pameijer, J.P.R. Herrman, V.A.W.M. Umans, J.W. Deckers. Data Coordinating and Analysis Center: Ciba-Geigy - P. Close, R. Kerry, P. Kobi, D. Bach, E. Grundl; Department of Clinical Epidemiology and Biostatistics, Cardialysis - R. Melkert. Hemostasis Core Laboratory (Department of Hemostasis and Thrombosis, Academic Medical Center, Amsterdam) - H. Büller. Safety Committee: K. Fox (chairman), H. Büller, D. Chamberlain (Royal Sussex County Hospital, Brighton, United Kingdom), Z. Pelikan (Medisch Centrum de Klokkenberg, Breda, the Netherlands), J. Tijssen (Academic Medical Center, Amsterdam). Critical Events Committee: H. Schmutzler (chairman) (Universitätsklinik Rudolf Virchow, Berlin), G. Heyndrickx, A. Zeiher, G. Specchia. Angiography Committee: R. Simon (chairman), V. Legrand, G.J. Laarman, H. Suryapranata. Study directors: J.W. Deckers, P. Close.

\section{REFERENCES}

1. Stein B, Fuster V, Israel DH, et al. Platelet inhibitor agents in cardiovascular disease: an update. J Am Coll Cardiol 1989;14:813-36.

2. Coller BS. Platelets and thrombolytic therapy. N Engl J Med 1990;322:3342.

3. Chesebro JH, Webster MWI, Zoldhelyi P, Roche PC, Badimon L, Badimon JJ. Antithrombotic therapy and progression of coronary artery disease: antiplatelet versus antithrombins. Circulation 1992;86:Suppl III:III-100-III110 .

4. Schwartz RS, Murphy JG, Edwards WD, Camrud AR, Vlietstra RE, Holmes DR. Restenosis after balloon angioplasty: a practical proliferative model in porcine coronary arteries. Circulation 1990;82:2190-200.

5. McNamara CA, Sarembock IJ, Gimple LW, Fenton JW II, Coughlin SR, Owens GK. Thrombin stimulation of smooth muscle cell proliferation is mediated by a cleavage-dependent, receptor mechanism. In: Abstracts of the Fourth Restenosis Summit, Cleveland, May 28-29, 1992. Cleveland: Cleveland Clinic Foundation, 1992:18. abstract.

6. Grutter MG, Priestle JP, Rahuel J, et al. Crystal structure of the thrombinhirudin complex: a novel mode of serine protease inhibition. EMBO J 1990; $8: 2361-5$

7. Weitz JI, Hudoba M, Massel D, Maraganore J, Hirsh J. Clot-bound thrombin is protected from inhibition by heparin-antithrombin III but is susceptible to inactivation by antithrombin III-independent inhibitors. J Clin Invest 1990; 86:385-91.

8. Heras M, Chesebro JH, Webster MWI, et al. Hirudin, heparin, and placebo during deep arterial injury in the pig: the in vivo role of thrombin in plateletmediated thrombosis. Circulation 1990;82:1476-84.

9. Sarembock IJ, Gertz SD, Gimple LW, Owen RM, Powers ER, Roberts WC. Effectiveness of recombinant desulphatohirudin in reducing restenosis after balloon angioplasty of atherosclerotic femoral arteries in rabbits. Circulation 1991;84:232-43.

10. Goldman L, Hashimoto B, Cook EF, Loscalzo A. Comparative reproducibility and validity of systems for assessing cardiovascular functional class: advantages of a new specific activity scale. Circulation 1981;64:122734.

11. Braunwald E. Unstable angina: a classification. Circulation 1989;80:410-4.

12. Close P, Bichler J, Kerry R, et al. Weak allergenicity of recombinant hirudin CGP 39393 (REVASC) in immunocompetent volunteers. Coron Artery Dis 1994;5:943-9.

13. Blackburn H, Keys A, Simonson E, Rautaharju P, Punsar S. The electrocardiogram in population studies: a classification system. Circulation 1960;21: 1160-75.

14. Hull R, Hirsch J, Jay R, et al. Different intensities of oral anticoagulant therapy in the treatment of proximal-vein thrombosis. N Engl J Med 1982;307: 1676-81.

15. Serruys PW, de Jaegere P, Kiemeneij F, et al. A comparison of balloonexpandable stent implantation with balloon angioplasty in patients with coronary artery disease. N Engl J Med 1994;331:489-95.

16. Serruys PW, Foley DP, de Feyter PJ, eds. Quantitative coronary angiography in clinical practice. Dordrecht, the Netherlands: Kluwer Academic Publishers, 1994. 
17. Kalbfleisch JD, Prentice RL. The statistical analysis of failure time data. New York: John Wiley, 1980

18. Schwartz L, Bourassa MG, Lespérance J, et al. Aspirin and dipyridamole in the prevention of restenosis after percutaneous transluminal coronary angioplasty. N Engl J Med 1988;318:1714-9.

19. Chesebro JH, Webster MWI, Reeder GS, et al. Coronary angioplasty: antiplatelet therapy reduces acute complications but not restenosis. Circulation 1989;80:Suppl II:II-64. abstract.

20. Bertrand ME, Allain H, Lablanche JM. Results of a randomized trial of ticlopidine versus placebo for prevention of acute closure and restenosis after coronary angioplasty (PTCA): the TACT study. Circulation 1990;82: Suppl III:III-190. abstract.

21. Topol EJ, Califf RM, Weisman HF, et al. Randomised trial of coronary intervention with antibody against platelet IIb/IIIa integrin for reduction of clinical restenosis: results at six months. Lancet 1994;343:881-6.

22. The EPIC Investigators. Use of a monoclonal antibody directed against the platelet glycoprotein IIb/IIIa receptor in high-risk coronary angioplasty. N Engl J Med 1994;330:956-61.

23. Verstraete M, Nurmohamed M, Kienast J, et al. Biologic effects of recombinant hirudin (CGP 39393) in human volunteers. J Am Coll Cardiol 1993; 22:1080-8.
24. Eriksson BI, Kälebo P, Ekman S, Lindbratt S, Kerry R, Close P. Direct thrombin inhibition with rec-hirudin CGP 39393 as prophylaxis of thromboembolic complications after total hip replacement. Thromb Haemost 1994; 72:227-31.

25. van den Bos AA, Deckers JW, Heyndrickx GR, et al. Safety and efficacy of recombinant hirudin (CGP 39 393) versus heparin in patients with stable angina undergoing coronary angioplasty. Circulation 1993;88:2058-66.

26. Zoldhelyi P, Bichler J, Owen WG, et al. Persistent thrombin generation in humans during specific thrombin inhibition with hirudin. Circulation 1994; 90:2671-8.

27. Chesebro JH, Badimon L, Fuster V. Importance of antithrombin therapy during coronary angioplasty. J Am Coll Cardiol 1991;17:Suppl B:96B-100B.

28. Wilentz JR, Sanborn TA, Haudenschild CC, Valeri CR, Ryan TJ, Faxon DP. Platelet accumulation in experimental angioplasty: time course and relation to vascular injury. Circulation 1987;75:636-42.

29. Groves HM, Kinlough-Rathbone RL, Mustard JF. Development of nonthrombogenicity of injured rabbit aortas despite inhibition of platelet adherence. Arteriosclerosis 1986;6:189-95.

30. Steele PM, Chesebro JH, Stanson AW, et al. Balloon angioplasty: natural history of the pathophysiological response to injury in a pig model. Circ Res $1985 ; 57: 105-12$ 